\title{
Possible effect of extreme solar energetic particle event of 20 January 2005 on polar stratospheric aerosols: direct observational evidence
}

\author{
I. A. Mironova ${ }^{1}$, I. G. Usoskin ${ }^{2,3}$, G. A. Kovaltsov ${ }^{4}$, and S. V. Petelina ${ }^{5}$ \\ ${ }^{1}$ Institute of Physics, St. Petersburg State University, St. Petersburg, Russia \\ ${ }^{2}$ Sodankylä Geophysical Observatory (Oulu unit), University of Oulu, Finland \\ ${ }^{3}$ Department of Physics, University of Oulu, Finland \\ ${ }^{4}$ Ioffe Physical-Technical Institute, St. Petersburg, Russia \\ ${ }^{5}$ Department of Physics, La Trobe University, Melbourne, Australia \\ Correspondence to: I. A. Mironova (mironova@geo.phys.spbu.ru) \\ Received: 1 April 2011 - Published in Atmos. Chem. Phys. Discuss.: 6 May 2011 \\ Revised: 24 November 2011 - Accepted: 28 November 2011 - Published: 17 January 2012
}

\begin{abstract}
Energetic cosmic rays are the main source of ionization of the low-middle atmosphere, leading to associated changes in atmospheric properties. Via the hypothetical influence of ionization on aerosol growth and facilitated formation of clouds, this may be an important indirect link relating solar variability to climate. This effect is highly debated, however, since the proposed theoretical mechanisms still remain illusive and qualitative, and observational evidence is inconclusive and controversial. Therefore, important questions regarding the existence and magnitude of the effect, and particularly the fraction of aerosol particles that can form and grow, are still open. Here we present empirical evidence of the possible effect caused by cosmic rays upon polar stratospheric aerosols, based on a case study of an extreme solar energetic particle (SEP) event of 20 January 2005. Using aerosol data obtained over polar regions from different satellites with optical instruments that were operating during January 2005, such as the Stratospheric Aerosol and Gas Experiment III (SAGE III), and Optical Spectrograph and Infrared Imaging System (OSIRIS), we found a significant simultaneous change in aerosol properties in both the Southern and Northern Polar regions in temporal association with the SEP event. We speculate that ionization of the atmosphere, which was abnormally high in the lower stratosphere during the extreme SEP event, might have led to formation of new particles and/or growth of preexisting ultrafine particles in the polar stratospheric region. However, a detailed interpretation of the effect is left for subsequent studies. This is the first time high vertical resolution measurements have been used to discuss possible production of stratospheric aerosols
\end{abstract}

under the influence of cosmic ray induced ionization. The observed effect is marginally detectable for the analyzed severe SEP event and can be undetectable for the majority of weak-moderate events. The present interpretation serves as a conservative upper limit of solar energetic particle effect upon polar stratospheric aerosols.

\section{Introduction}

Cosmic rays are energetic particles (mostly protons and $\alpha$-particles) of extra-terrestrial origin impinging upon the Earth's atmosphere. They are categorized according to their origin as either galactic cosmic rays (GCRs) or solar cosmic rays, the latter more conventionally referred to as solar energetic particles (SEPs). The primary effect of cosmic rays in the atmosphere is ionization of the ambient air (see, e.g. a review by Bazilevskaya et al., 2008), and this is the main source of ionization in the low and middle atmosphere. GCRs are always present in the Earth's vicinity, and their atmospheric effect is roughly constant, with the range of variations being within 10-20\%. SEPs occur sporadically, usually in conjunction with giant eruptive events (solar flares or coronal mass ejections) at the Sun. SEPs are less energetic (typically protons with energy below $1 \mathrm{GeV}$ ) than GCRs but may produce fluxes exceeding those of GCRs by orders of magnitude during hours-days. Because of their lower energy, SEPs can penetrate into the Earth's atmosphere only in the polar regions where there is no shielding of the geomagnetic field, and they generally affect only 
the mesosphere and stratosphere above about $20 \mathrm{~km}$ (Vitt and Jackman, 1996). However, there is a special class of SEP events, called Ground Level Enhancements (GLEs), which are characterized by the presence of very energetic particles (up to several $\mathrm{GeV}$ ) that can cause a noticeable effect at the ground level, as observed by neutron monitors (e.g. Shea and Smart, 1990). Because the energetic particle flux varies greatly during short time intervals, GLEs provide a good opportunity for case studies of atmospheric effects.

Many studies have been done on the SEP influence on such atmospheric constituents as $\mathrm{HO}_{\mathrm{x}}, \mathrm{NO}_{\mathrm{x}}$ and $\mathrm{O}_{3}$ in the polar mesosphere and stratosphere (e.g. Krivolutsky et al., 2003; Semeniuk et al., 2005; Jackman et al., 2005; Randall et al., 2007; Seppälä et al., 2008). Such chemical changes are usually reasonably represented in global chemistry climate models (e.g. Semeniuk et al., 2005; Krivolutsky et al., 2006; Jackman et al., 2008). However, the issue of a possible influence of energetic particles, mostly GCR, on cloud and aerosol properties in the lower atmosphere (lower stratosphere and troposphere) is still debated (e.g. Kulmala et al., 2010). Although there are some hints that atmospheric ionization due to cosmic rays may affect aerosol particles and/or clouds in the troposphere and stratosphere (e.g. Carslaw et al., 2002; Arnold, 2006; Curtius et al., 2006; Kazil et al., 2008; Harrison and Tammet, 2008), it is difficult to get clear experimental evidence. Comparisons of inter-annual variability in solar activity or cosmic rays and cloud data (e.g. Pallé et al., 2004; Usoskin et al., 2006; Voiculescu et al., 2006; Kulmala et al., 2010) lead to ambiguous interpretations because of the natural climate variability modes operating on the same time scales (e.g. Voiculescu et al., 2007). It is common to study the relation between aerosols or different types of clouds and short-term suppressions of GCR flux during Forbush decreases caused by strong interplanetary transients. Such studies are numerous (e.g. Kniveton, 2004; Kristjánsson et al., 2008; Pierce and Adams, 2009; Svensmark et al., 2009; Laken et al., 2009; Calogovic et al., 2010) but also highly controversial and inconclusive. Moreover, they are looking for a possible disappearance of existing aerosols or cloud condensation nuclei $(\mathrm{CCN})$ associated with a reduction in the GCR flux, which may be quite different from production of new particles by enhanced flux. In this sense, it is more promising to perform a case study of the potential atmospheric response to a strong GLE event. For a detailed analysis we have chosen the time period of January 2005, which is characterized by a strong burst of solar activity, including an extreme GLE/SEP event of January 20, 2005. That event was analyzed earlier by Mironova et al. (2008) who found, using the Total Ozone Mapping Spectrometer (TOMS) data obtained by the Earth Probe Satellite, an increase in the overall aerosol optical depth in the southern polar region associated with the event. The observed changes could not be explained by modeled downward propagation of the chemical changes induced by the same GLE in the mesosphere (Seppälä et al., 2008), and thus were thought to be

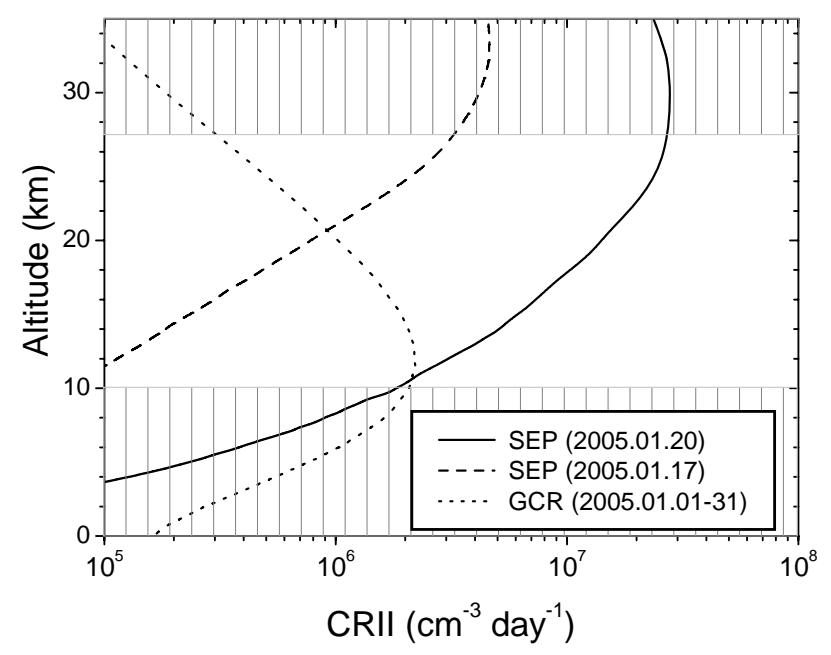

Fig. 1. Daily integrated cosmic ray induced ionization (CRII) of the polar atmosphere in January 2005. Solid and dashed curves depict the net ionization due to two SEP events, of 20 January and 17 January (a typical event), respectively. The dotted curve depicts the average ionization rate due to galactic cosmic rays in January 2005.

associated with the direct additional ionization of the stratosphere by SEP. The analysis by Mironova et al. (2008) was, however, limited to only the southern polar region and provided no altitudinal information; therefore, precise attribution of the aerosol changes to enhanced GLE-induced ionization in the lower stratosphere was not possible.

Here we look for a possible influence of a sudden dramatic increase in atmospheric ionization due to the extreme SEP/GLE event of 20 January 2005 on the behavior of aerosol particles in the polar lower stratosphere. We base our analysis on satellite aerosol data that allow investigation of the behavior of aerosol components in both polar hemispheres with high vertical resolution.

\section{Time interval of January 2005}

The SEP event of 20 January 2005 was recorded as a very high count rate at the ground-level network of neutron monitors and was one of the strongest GLE events ever observed (Mewaldt et al., 2007). This event was highly anisotropic and asymmetric in the short impulsive phase; in particular, the peak enhancement was stronger in the Southern Polar region (almost $3500 \%$ at the South Pole station) than in the Northern one (about $300 \%$ at the Oulu station) during the impulsive phase of the event (e.g. Plainaki et al., 2007; Bütikofer et al., 2008). During the main phase the GLE event was fairly isotropic, leading to similar enhancements in both regions. The GLE occurred on 20 January 2005: began at about 06:50 UT, with the peak intensity reached at 07:00-07:10 UT, DOY (day of year) 20.3. This was followed by a second lower peak 
at about 09:00 UT and a gradual decay until about mid-day of 20 January. The very high level of neutron monitor count rate increase implies that the ionization of the polar atmosphere was dramatically increased during the event (Vainio et al., 2009). Atmospheric ionization during this event has been discussed in great detail by Usoskin et al. (2011a). This is illustrated in Fig. 1, showing that the calculated ionization due to the SEP event of 20 January started dominating over the GCR ionization already at $10-\mathrm{km}$ altitude and reached its maximum at about $30 \mathrm{~km}$ altitude. These computations have been performed using the CRAC:CRII (Cosmic Ray induced Atmospheric Cascade: application for Cosmic Ray Induced Ionization) model (Usoskin and Kovaltsov, 2006; Usoskin et al., 2010), energy spectra of SEP provided by Tylka and Dietrich (2009) and Usoskin et al. (2011a), and GCR according to Usoskin et al. (2005, 2011b). The altitude range analyzed in this study is not hatched. In particular, the CRAC:CRII model calculations suggest that the SEP event produced additional ionization in the polar atmosphere in the altitude range $12-23 \mathrm{~km}$, with the number of ions being greater by a factor of 3-30 than the averaged GCR-induced daily ionization in January 2005. So high a level of atmospheric ionization is reached very rarely and thus makes it possible to study the proposed relation in detail. However, this enhanced ionization existed only in the polar region above $\approx 60^{\circ}$ magnetic latitude. At lower latitudes and altitudes, the ionization was reduced due to the relatively strong Forbush decrease (about $15 \%$ ) that started on 17 January in association with a medium-size SEP event (Bazilevskaya et al., 2008). We note that the previous SEP event of 17 January had a much softer spectrum. Although its columnar ionization rate was larger than that computed for the 20 January event (Seppälä et al., 2006; Jackman et al., 2011), it was mostly in the upper atmosphere (above $40 \mathrm{~km}$ ), while the 20 January event was dominant in the height range studied here (see Fig. 1). Before 17 January and after 24 January, the cosmic ray flux remained fairly stable. Ionization due to the SEP event of 20 January dominates over the GCR ionization at altitudes above $10 \mathrm{~km}$.

\section{Remote sensing of the atmosphere during January 2005}

To complement our previous work (Mironova et al., 2008), which was based on TOMS data providing the integrated aerosol optical depth, here we analyze vertical profiles of stratospheric aerosol properties in January 2005. The analyses are based on data from the third Stratospheric Aerosol and Gas Experiment (SAGE III) and the Optical Spectrograph and Infrared Imaging System (OSIRIS). We also investigated data from the Polar Ozone and Aerosol Measurement (POAM III) instrument. However, the latter results are disregarded since POAM aerosol data were affected by a sporadic mechanical problem in the instrument during the second half of January 2005 (C. Randall and K. Hoppel, personal communication, 2010). We have checked also other data sets potentially providing data for that period and found that only the data sets discussed here can be used for our study.

\subsection{SAGE aerosol data}

The NASA SAGE III instrument (hereinafter referred to as SAGE) was launched onboard the Russian Meteor-3M satellite into a sun synchronous orbit with an inclination of $99.53^{\circ}$ ) (see, e.g. Yue et al., 2005); it was terminated in March 2006. Accordingly, the satellite scans the entire longitudinal range during $24 \mathrm{~h}$. The SAGE III data have been obtained from NASA Langley Atmospheric Sciences Data Center http://www-sage3.larc.nasa.gov. SAGE is a solar occultation instrument, so aerosol properties are inferred from measurements of the spectral extinction of solar radiation as it is transmitted through the atmosphere. It makes measurements at equally spaced longitudes around a circle of approximately constant latitude in each hemisphere on each day. Measurement latitudes change slowly throughout the year, ranging from about $45^{\circ}-80^{\circ} \mathrm{N}$ in the Northern Hemisphere and from about $35^{\circ}-60^{\circ} \mathrm{S}$ in the Southern Hemisphere. During the month of January 2005, the measurement latitudes ranged from $66.0^{\circ}$ to $72.8^{\circ} \mathrm{N}$ in the north and from $36.8^{\circ}$ to $37.8^{\circ} \mathrm{S}$ in the south. Thus, no observations were made at the high southern latitudes of interest for this work. The vertical profile of SAGE aerosol extinction profiles is given in the range from 10 to $45 \mathrm{~km}$ height with the vertical resolution $0.5 \mathrm{~km}$ (Yue et al., 2005). The aerosol extinction coefficient (AEC, in $\mathrm{km}^{-1}$ ) was obtained in nine wavelength channels: $385,449,521,602,676,756,869,1020$ and $1550 \mathrm{~nm}$.

\subsection{OSIRIS aerosol data}

OSIRIS was launched onboard the Odin satellite into a sunsynchronous orbit with an inclination of $98^{\circ}$ in February 2001. It scans the Earth's limb between 6 and 60 (or $110) \mathrm{km}$ and measures the atmospheric limb-scattered sunlight (Llewellyn et al., 2004). Details of the OSIRIS aerosol retrieval algorithm are described by Bourassa et al. (2007). OSIRIS samples latitudes from $82^{\circ} \mathrm{S}$ to $82^{\circ} \mathrm{N}$ on a daily basis, but because of the satellite local time and requirement for sunlight, the latitudes of the aerosol retrievals are restricted. Thus, aerosol properties at polar latitudes in January 2005 were only obtained in the Southern Hemisphere. We analyze here the OSIRIS aerosol extinction coefficient data for January 2005 from $60^{\circ} \mathrm{S}$ to $89^{\circ} \mathrm{S}$. The AEC data are considered in the altitude range $11-28 \mathrm{~km}$ with a vertical resolution of $1 \mathrm{~km}$ (Bourassa et al., 2007). OSIRIS data on AEC are only available at the $750 \mathrm{~nm}$ wavelength.

We note that the OSIRIS CCD detector can potentially be affected by SEP, as some energetic particles may cause temporary spikes in one, or more, of its pixels. We carefully examined the vertical profiles for Level 1 radiances that were 


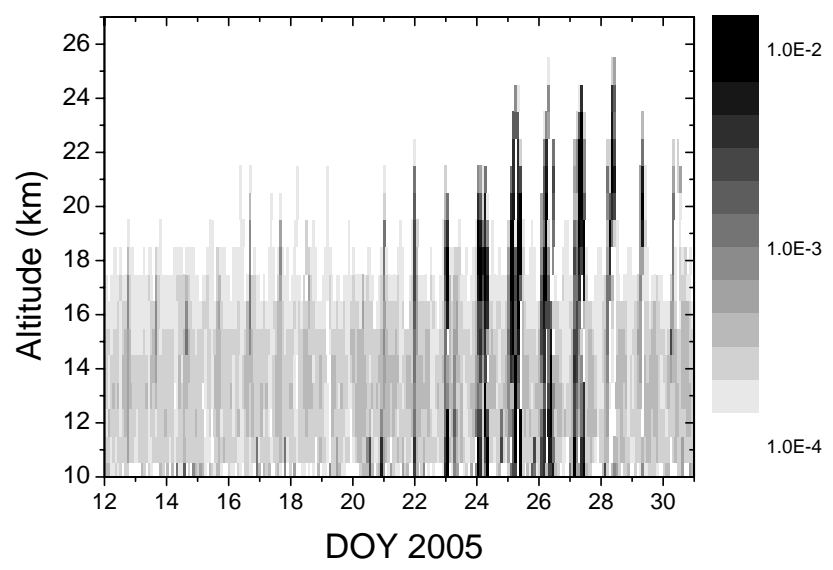

Fig. 2. Vertical profiles of aerosol extinction coefficient (in $\mathrm{km}^{-1}$ ) at the $756 \mathrm{~nm}$ wavelength measured by SAGE III in the Northern Polar region (zonal mean, 66-72 ${ }^{\circ} \mathrm{N}$ ) during 13-30 January 2005. Logarithmic grey scale is shown on the right panel.

used for aerosol extinction retrievals and found that the effect of SEP on Level 1 data below $30 \mathrm{~km}$ was insignificant. Namely, the additional signal caused by occasional spikes was at least 150 times smaller than signal below $30 \mathrm{~km}$.

Thus, the work described below uses SAGE III data for the Northern Hemisphere and OSIRIS data for the Southern Hemisphere.

\subsection{Meteorological parameters}

Meteorological parameters such as altitude profiles of pressure, temperature, and potential vorticity were obtained from the Met Office (MetO, http://www.metoffice.gov.uk/) meteorological assimilation data and interpolated to the measurement locations.

\section{Aerosol properties associated with 20 January 2005 GLE event}

\subsection{Northern Hemisphere}

For the Northern Hemisphere we possess data from SAGE III instrument. As an example, we show in Fig. 2 changes of the AEC in the wavelength $756 \mathrm{~nm}$ in the Northern Polar region (longitudinal information is not considered in this plot). This wavelength is close to that of the OSIRIS discussed in Sect. 4.2. One can see a strong (up to a factor of 100) apparent increase of AEC since 20-21 January until ca. 27 January in the altitude range $10-22 \mathrm{~km}$. On the other hand, one can see that the AEC increase is not uniform but seemingly intermittent. This pattern is related to the spatial inhomogeneity of the aerosol features and the fact that the satellite continuously scans different longitudes.
In order to illustrate that, we show in Fig. 3 AEC at the same wavelength $(756 \mathrm{~nm})$ but now fixing altitudes and considering longitudinal variability (the latitude is always in a narrow band of $66-73^{\circ} \mathrm{N}$ ). One can see that the strong increase of AEC was detected starting day 21 but only in a limited longitudinal range from about $30^{\circ} \mathrm{W}$ to $90^{\circ} \mathrm{E}$, while in other regions there is no notable effect. The maximum effect is observed 2-4 days after the GLE event. This longitudinal feature is quite stable, ranging from 10 to about $20-22 \mathrm{~km}$ in altitude and being present for a week. For further analysis, we consider this longitudinal range, viz. $30^{\circ} \mathrm{W}-90^{\circ} \mathrm{E}$ and $66-73^{\circ} \mathrm{N}$, corresponding to NW Eurasia from Greenland to mid-Siberia.

The log-log slope of the AEC as function of wavelength is called the Ångstrom exponent $\alpha$ and reflects the size distribution of the scattering particles. Here we computed the value of $\alpha$ using all the wavelength channels. Since uncertainties in AEC depend on wavelength, we used the standard weighted least squares method to calculate the best fit power-law regression and its uncertainty, using the nine SAGE wavelength channels noted above (see an example in Fig. 4). We applied this method even when data in some channels were missing. If, however, the number of available wavelengths was reduced to three or less, such a data point was discarded from further analysis.

The value of $\alpha$ depends on the particle size distribution, so that the larger $\alpha$ is, the smaller the particles are. For example, for particles with the diameter larger than the maximum wavelength, the AEC does not depend on the wavelength, i.e. $\alpha \approx 0$. In the framework of standard idealistic Mie theory, some estimates on the particle size can be made. However, here we consider only possible qualitative changes in the features of the scattering particles, since any quantitative values depend on the underlying assumptions on unknown parameters.

Figure 5 shows the temporal and latitudinal changes of the Angstrom exponent $\alpha$ for the selected geographical region (panel A) and for the entire Northern Polar region (panel B). One can see a small, but significant, increase of the $\alpha$ since 21-22 January in the altitude range $15-20 \mathrm{~km}$. The increase of $\alpha$ from $\approx 1.5$ to 2.5 suggests that the effective size of scattering particles somewhat decreased, which can be interpreted as possible production (or growth from below detection threshold) of ultrafine particles, probably along with the simultaneous increase of the total aerosol mass. This feature was persistent for a week and then disappeared, viz. the size of particles restored to its normal value. In the selected geographical region in NW Eurasia (Fig. 5a), the pattern was different. A slight increase in $\alpha$ already started on 20 January, the day of the GLE event, at $15-17 \mathrm{~km}$ height and remained for 3-4 days. It changed on 24-25 January, when the value of $\alpha$ dramatically decreased to nearly 0 with the lowering of the affected region by a few $\mathrm{km}$. Such a low value of $\alpha$ indicates a sudden increase of the effective aerosol size up to several hundred nm or more (comparable to the wavelength range of 

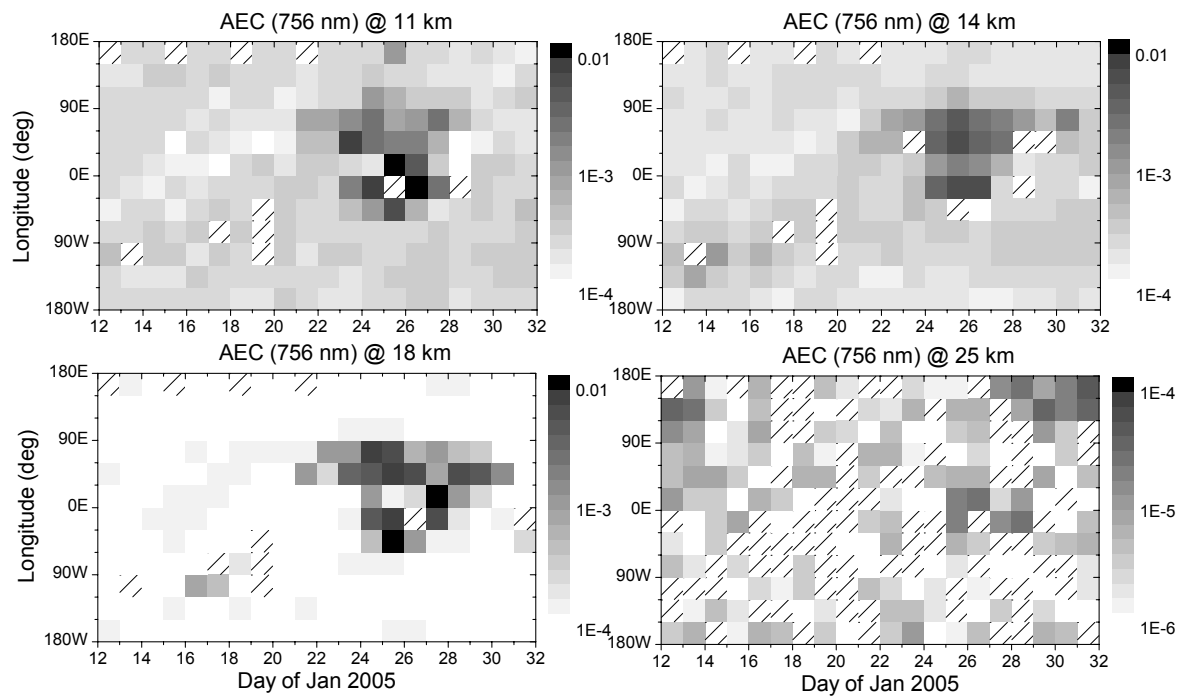

Fig. 3. Daily averaged aerosol extinction coefficient (in $\mathrm{km}^{-1}$ ) at the $756 \mathrm{~nm}$ wavelength measured by SAGE III instrument at fixed altitudes (as denoted on top of each panel) as a function of geographical longitude. Logarithmic grey scale is shown on the right of each panel.

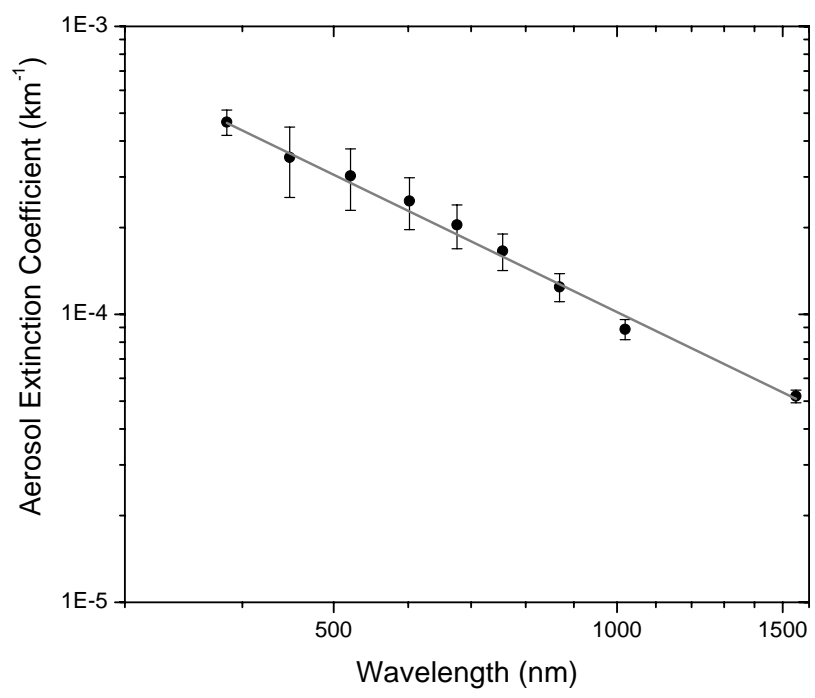

Fig. 4. An example of wavelength dependence of SAGE aerosol extinction coefficients (1 January 2005 at height $15.25 \mathrm{~km}$ ). Solid line corresponds to the best fit power law (Ångstrom exponent) $\alpha=$ $1.58 \pm 0.05$.

the SAGE experiment), i.e. to the size of ice particles forming clouds at this height. We note that such a dramatic change is observed only in the region of NW Eurasia.

We have also checked the meteorological conditions in the Northern Polar region during January 2005, which was the middle of the Boreal winter. Spatial and temporal variability of the temperature is plotted in Fig. 6. First half of the month in the NW Eurasian region, between DOY 1 and 15 in the altitudes range from 14 to $25 \mathrm{~km}$ (see panels $\mathrm{B}, \mathrm{C}$ and D), was characterized by temperatures below $\approx 200 \mathrm{~K}$, that could lead to formation of PSCs (Polar Stratospheric Clouds). We note that the NH winter of 2004-2005 was exceptionally cold with enhanced PSC occurrence (e.g. Sonkaew et al., 2011; Polyakov et al., 2008; European Ozone Research Coordinating Unit, 2005). Another cooling by about $10 \mathrm{~K}$ was observed in the NW Eurasian region in the entire altitude range from 10 to $25 \mathrm{~km}$ a few days after the GLE event, on 2324 January, when the temperature dropped again to $200 \mathrm{~K}$ and below, leading to formation of PSCs (and thus $\alpha \approx 0$ ) in that region after DOY 25 (Fig. 5). However, since PSCs were formed on DOY 25, they cannot explain the observed Ångstrom exponent change during DOY 22-24.

In order to exclude that the observed phenomenon is a typical mid-winter/summer effect due to, e.g. a change in insolation of the polar atmosphere, we have checked the period of mid-summer/winter (January and July) for other years (1998-2003) using also POAM data (C. Randall, personal communication 2010). No change of the aerosol index similar to that discussed here have been found for all other years, suggesting that this is not a typical mid-winter feature.

We can briefly summarize the observations in the Northern Polar region as follows.

- A weak increase in the Ångstrom exponent over all longitudes started on DOY 22, i.e. 2 days after the GLE event, in the entire Northern Polar region at altitudes $15-20 \mathrm{~km}$. It was accompanied by an increase of AEC, mostly in shorter wavelength, indicating a larger number of particles. Such behavior is interpreted as a possible decrease in the effective size of aerosols due to production of new ultrafine particles within 1-2 days after the GLE event in the entire Northern Hemisphere region. 

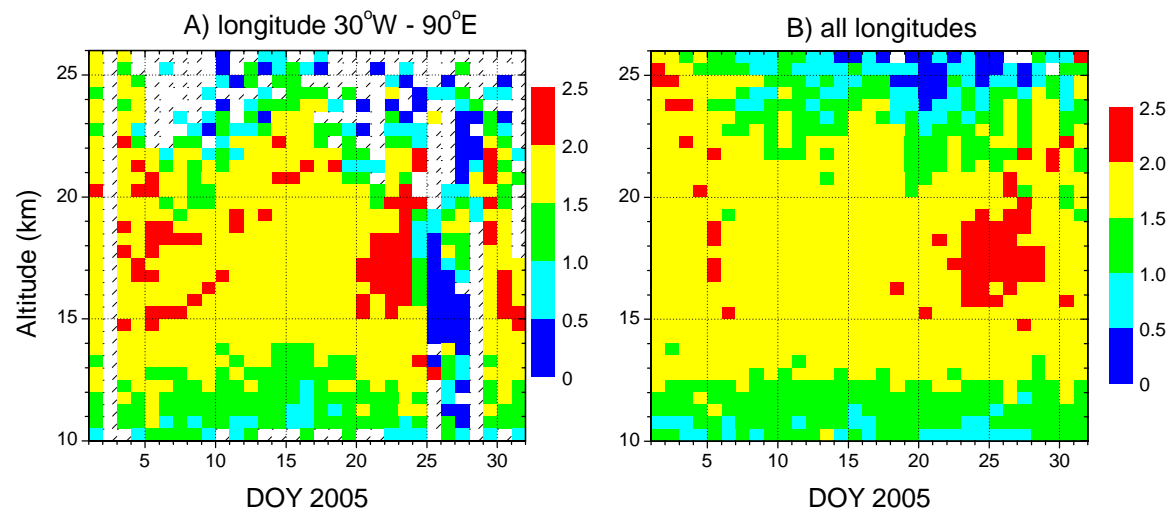

Fig. 5. Angstrom exponent $\alpha$ calculated from SAGE III aerosol extinction as a function of altitude and time. Data were averaged over the longitudinal region $30^{\circ} \mathrm{W}-90^{\circ} \mathrm{E}(\mathbf{A})$ and all longitudes (B) in the Northern Polar region (latitude 66-73 $)$.
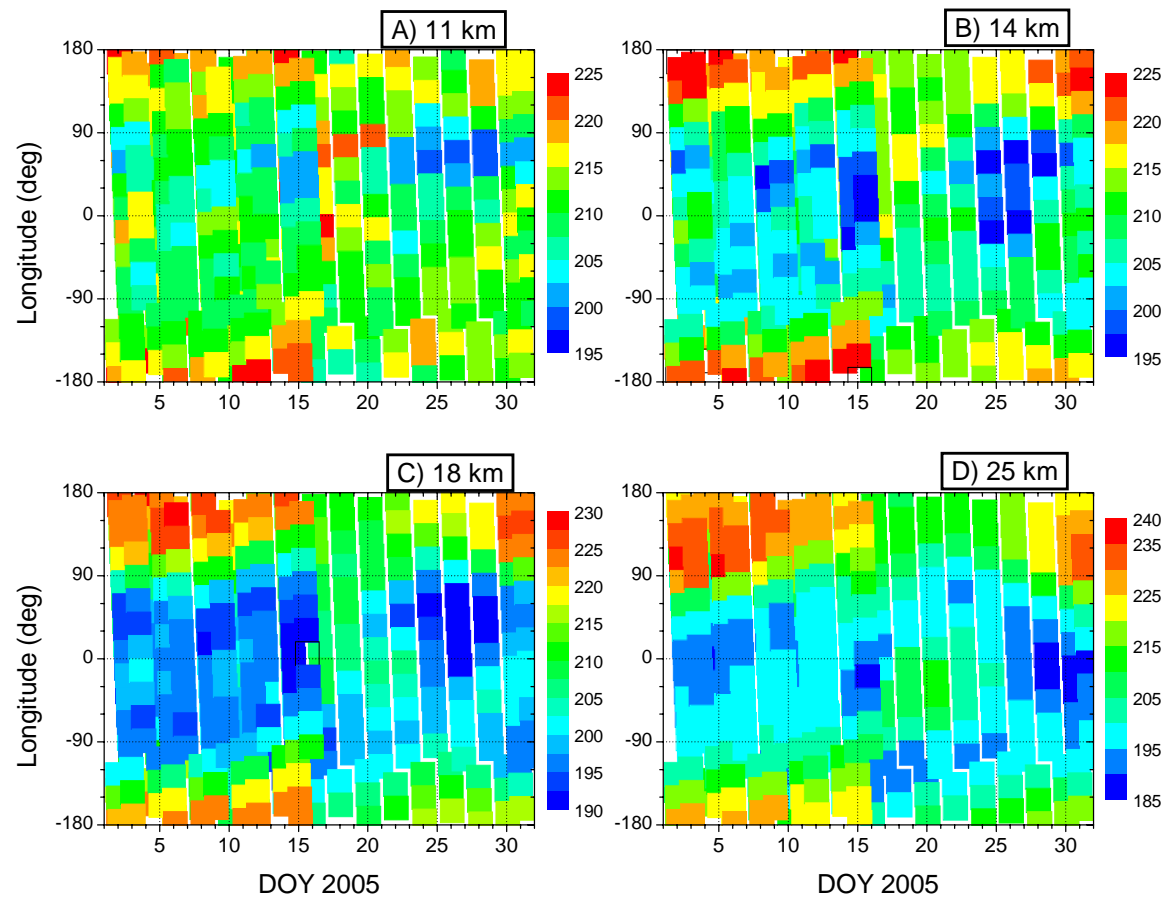

Fig. 6. Temperature distribution in the Northern Polar stratosphere as a function of geographical longitude and time, for four fixed altitudes as indicated on top of each panel. Color scale is shown to the right of each panel.

- A peculiar region, NW Eurasia $\left(30^{\circ} \mathrm{W}-90^{\circ} \mathrm{E}\right)$, can be identified, where this effect was followed by an essential growth and sedimentation of aerosols, related to the formation of polar stratospheric clouds (PSC) on DOY 25 . The PSCs were caused by cooling of that region.

\subsection{Southern Hemisphere}

For the Southern Hemisphere, we possess data from the OSIRIS instrument, which is only available at one wavelength. In Fig. 7, we plotted the AEC profile at $750 \mathrm{~nm}$ measured by OSIRIS in the Antarctic polar region (longitudinal information is not considered in this plot) for DOY $16-31$. The AEC depicted an essential (nearly two orders of magnitude between 11 and $28 \mathrm{~km}$ ) altitudinal gradient (see panel A). Consequently, on panel B we show normalized (to the mean profile shown in panel A) daily AEC profiles. One 


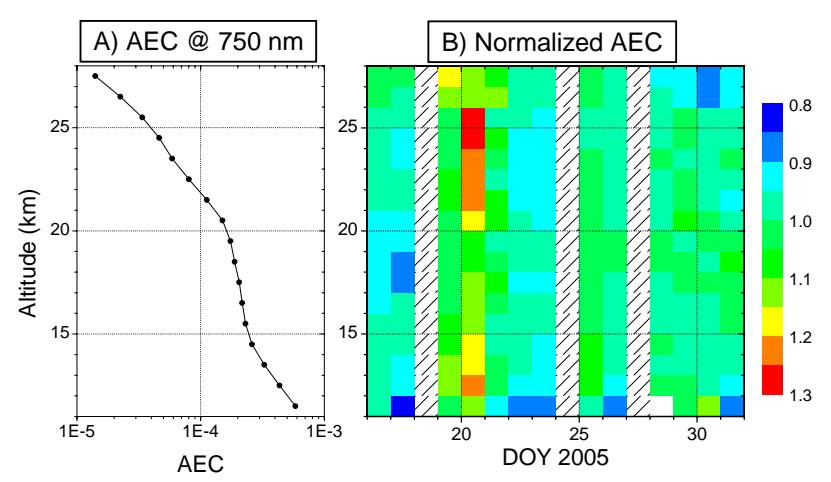

Fig. 7. Averaged OSIRIS aerosol extinction (in $\mathrm{km}^{-1}$ ) profiles at $750 \mathrm{~nm}$ measured over the Antarctic region in the second half of January 2005. (A) The average profile for the 16-31 January 2005 period. (B) Normalized (to that shown in A) daily averaged AEC. Hatched area depicts days with no data available.

can see a systematic increase in the AEC on the very day of January 20 with the maximum around $25 \mathrm{~km}$, extended down to $12 \mathrm{~km}$. However, this increase in AEC was relatively small (maximum $30 \%$ ) compared to an order of magnitude increase in the Arctic region (Sect. 4.1) and vanished within one day. This suggests that an increase in AEC (or in the particles' size/volume) could be caused by the direct effect of GLE in the lower stratosphere, but the ambient conditions were not favorable to develop the effect further at least for larger particles, as observed at $750 \mathrm{~nm}$ wavelength by OSIRIS. No specific longitudinal pattern has been found in the OSIRIS data for the period under question. We have also checked that there was no volcanic eruption or extensive bushfires able to mimic the observed changes. On the other hand, it was found out earlier (Mironova et al., 2008), using TOMS data, that the aerosol optical depth at the wavelength of about $360 \mathrm{~nm}$ increased in the Antarctic region on the second day after the GLE, i.e. on 20 January 2005, and that the increase was statistically significant. This suggests that smaller particles affecting the optical depth at $360 \mathrm{~nm}$ wavelength but undetectable at $750 \mathrm{~nm}$, were able to develop, reaching the maximum effect on the second day after the GLE event. Unfortunately, the earlier study did not provide vertical profiles of the effect because of the method used by the TOMS instrument.

\section{Discussion and conclusions}

We have analyzed available data of the aerosol properties in the two polar regions for the period of January 2005 when an extreme GLE event of solar energetic particles took place.

We found a change in the aerosol optical properties and Ångstrom exponent and try to speculate on its possible implications. First, smaller particles formed, leading to a seemingly decrease in the value of aerosol effective size after the SEP event. Several days later, the effect was also observed for larger particles, but it was most likely related to an independent cooling event. This was accompanied by the growth by an order of magnitude of the AEC at all wavelengths. A possible explanation for the observed "downsizing" of aerosol particles, based on the increasing Ångstrom exponent, is one, or a combination, of the following:

1. break-up of large particles into smaller ones;

2. formation of new (small) particles;

3. growth of pre-existing particles, whose size was below the satellite-based instruments detection threshold, before SEP;

4. transport of particles from elsewhere.

Explanations (2) and/or (3) are more appealing for the following reasons. First, it is known that atmospheric ions can grow efficiently into stable aerosol particles (Arnold, 2008), and the SEP provided the required ionization. Second, the observed effects on the SAGE III and OSIRIS data were similar and took place concurrently in both polar regions, despite quite different meteorological conditions. Because of the polar vortex, we do not expect essential latitudinal transport, while the effect is observed in the entire polar region.

Timing of the aerosol response deserves a separate discussion. In our earlier study (Mironova et al., 2008), we found that a decrease in aerosol index (increase in the number of small particles, like sulfates) over places with the maximum ionization rate reached its maximum on the second day after GLE. However, in that work we studied the entire aerosol optical depth, corresponding mainly to the troposphere, while here we focus on the aerosol response to increasing cosmic ray induced ionization (CRII) in the lower and middle stratosphere. In the present study, we observed the aerosol response within one day of the GLE. There is also a tendency for the maximum effect to be observed with a few days delay at lower altitudes below $23 \mathrm{~km}$ for the Northern Polar Hemisphere, especially in the Ångstrom exponent (see Fig. 5). The exact time of the maximum response of aerosols to GLE is, however, difficult to derive. According to some numerical simulations (e.g. Arnold, 2008) for the upper troposphere, the CRII rate of about $30-40 \mathrm{~cm}^{-3} \mathrm{~s}^{-1}$ would lead to a possible reaction of aerosol particles delayed by 1-6 days, depending on the size of fractions. This is consistent with a 2-3 days delay observed here.

In conclusion, we have presented the result of an analysis of empirical data for a possible direct influence of the extreme SEP/GLE event of 20 January 2005 on aerosol parameters in the polar stratosphere (altitudes between 11 and $25 \mathrm{~km}$ ). This may be speculated as a possible nearly simultaneous growth, in both polar regions, of ultrafine particles. This aerosol response was under stable atmospherical conditions and associated with the extreme event, when the ionization due to SEP was several orders of magnitude greater 
than typical values due to galactic cosmic rays (see Fig. 1). Although a detailed mechanism of such effects is not well understood yet, there is some theoretical (e.g. Kazil et al., 2008) and also empirical (Duplissy et al., 2010; Nieminen et al., 2011) evidence that an enhanced ionization may facilitate growth of ultrafine aerosols if the meteorological conditions remain constant. We note that, while the observational result is novel and robust, the possible explanation proposed here is only a qualitative speculation. Since we assume that the observed changes are caused solely by the energetic particles, this serves as a conservative upper limit of solar energetic particle effect upon polar stratospheric aerosols. More detailed modeling is required in order to fully understand the found effect.

We would also like to emphasize that the observed atmospheric effect for this extreme GLE event was barely significant. No clear lower stratospheric effect was found beyond statistical fluctuations for the SEP event of 17 January 2005, which had a much smaller flux of the highest energy protons. This implies that only extremely hard-spectrum (high energy) GLE/SEP events can produce a noticeable direct effect on aerosols in the polar low-middle stratosphere.

Acknowledgements. We thank Cora Randall for invaluably useful discussions and consultations on the POAM data. Frank Arnold is thanked for stimulating discussions. Valuable advices of Jeffrey Pierce are thankfully acknowledged. IM acknowledges Alexander Smirnov and Alexey Chayka for useful discussions. The SAGE III data have been obtained from NASA Langley Atmospheric Sciences Data Center. The OSIRIS data have been obtained from http://osirus.usask.ca. OSIRIS is presently a third-party mission the European Space Agency. Support from the Academy of Finland is gratefully acknowledged. This work of IM is also supported by grants 11.37.26.2011 and 11.42.503.2011 of St. Petersburg State University. The present work was performed in relation with the following international Programmes: CAWSES-II and COST ES0803 and ES1005. IM and IU acknowledge useful discussions within the ISSI Team on Study of Cosmic Ray Influence upon Atmospheric Processes. We thank anonymous referees and the Editor Ilona Riipinen for useful comments and suggestions that led to essential improvement of this paper.

Edited by: I. Riipinen

\section{References}

Arnold, F.: Atmospheric Aerosol and Cloud Condensation Nuclei Formation: A Possible Influence of Cosmic Rays?, Space Sci. Rev., 125, 169-186, 2006.

Arnold, F.: Atmospheric Ions and Aerosol Formation, Space Sci. Rev., 137, 225-239, doi:10.1007/s11214-008-9390-8, 2008.

Bazilevskaya, G. A., Usoskin, I. G., Flückiger, E. O., Harrison, R. G., Desorgher, L., Bütikofer, R., Krainev, M. B., Makhmutov, V. S., Stozhkov, Y. I., Svirzhevskaya, A. K., Svirzhevsky, N. S., and Kovaltsov, G. A.: Cosmic Ray Induced Ion Production in the Atmosphere, Space Sci. Rev., 137, 149-173, 2008.
Bourassa, A. E., Degenstein, D. A., Gattinger, R. L., and Llewellyn, E. J.: Stratospheric aerosol retrieval with optical spectrograph and infrared imaging system limb scatter measurements, J. Geophys. Res., 112, D10217, doi:10.1029/2006JD008079, 2007.

Bütikofer, R., Flückiger, E., Desorgher, L., and Moser, M.: The extreme solar cosmic ray particle event on January 2005 and its influence on the radiation dose rate at aircraft altitude, Sci. Total Environ., 391, 177-183, 2008.

Calogovic, J., Albert, C., Arnold, F., Beer, J., Desorgher, L., and Flueckiger, E. O.: Sudden cosmic ray decreases: No change of global cloud cover, Geophys. Res. Lett., 37, L03802, doi:10.1029/2009GL041327, 2010.

Carslaw, K. S., Harrison, R. G., and Kirkby, J.: Cosmic Rays, Clouds, and Climate, Science, 298, 1732-1737, doi:10.1126/science.1076964, 2002.

Curtius, J., Lovejoy, E. R., and Froyd, K. D.: Atmospheric Ioninduced Aerosol Nucleation, Space Sci. Rev., 125, 159-167, 2006.

Duplissy, J., Enghoff, M. B., Aplin, K. L., Arnold, F., Aufmhoff, H., Avngaard, M., Baltensperger, U., Bondo, T., Bingham, R., Carslaw, K., Curtius, J., David, A., Fastrup, B., Gagné, S., Hahn, F., Harrison, R. G., Kellett, B., Kirkby, J., Kulmala, M., Laakso, L., Laaksonen, A., Lillestol, E., Lockwood, M., Mäkelä, J., Makhmutov, V., Marsh, N. D., Nieminen, T., Onnela, A., Pedersen, E., Pedersen, J. O. P., Polny, J., Reichl, U., Seinfeld, J. H., Sipilä, M., Stozhkov, Y., Stratmann, F., Svensmark, H., Svensmark, J., Veenhof, R., Verheggen, B., Viisanen, Y., Wagner, P. E., Wehrle, G., Weingartner, E., Wex, H., Wilhelmsson, M., and Winkler, P. M.: Results from the CERN pilot CLOUD experiment, Atmos. Chem. Phys., 10, 1635-1647, doi:10.5194/acp-101635-2010, 2010.

European Ozone Research Coordinating Unit: The Northern Hemisphere stratosphere in the 2004/05 winter, technical report, Dep. of Chem., Univ. of Cambridge, UK, available at: http://www. ozone-sec.ch.cam.ac.uk/EORCU/reports/wr0405.pdf, 2005.

Harrison, R. G. and Tammet, H.: Ions in the Terrestrial Atmosphere and Other Solar System Atmospheres, Space Sci. Rev., 137, 107 118, 2008.

Jackman, C. H., Deland, M. T., Labow, G. J., Fleming, E. L., Weisenstein, D. K., Ko, M. K. W., Sinnhuber, M., Anderson, J., and Russell, J. M.: The influence of the several very large solar proton events in years 20002003 on the neutral middle atmosphere, Adv. Space Res., 35, 445-450, 2005.

Jackman, C. H., Marsh, D. R., Vitt, F. M., Garcia, R. R., Fleming, E. L., Labow, G. J., Randall, C. E., López-Puertas, M., Funke, B., von Clarmann, T., and Stiller, G. P.: Short- and medium-term atmospheric constituent effects of very large solar proton events, Atmos. Chem. Phys., 8, 765-785, doi:10.5194/acp-8-765-2008, 2008.

Jackman, C. H., Marsh, D. R., Vitt, F. M., Roble, R. G., Randall, C. E., Bernath, P. F., Funke, B., López-Puertas, M., Versick, S., Stiller, G. P., Tylka, A. J., and Fleming, E. L.: Northern Hemisphere atmospheric influence of the solar proton events and ground level enhancement in January 2005, Atmos. Chem. Phys., 11, 6153-6166, doi:10.5194/acp-11-6153-2011, 2011.

Kazil, J., Harrison, R. G., and Lovejoy, E. R.: Tropospheric New Particle Formation and the Role of Ions, Space Sci. Rev., 137, 241-255, 2008.

Kniveton, D. R.: Precipitation, cloud cover and Forbush decreases 
in galactic cosmic rays, J. Atmos. Solar-Terr. Phys., 66, 11351142, 2004.

Kristjánsson, J. E., Stjern, C. W., Stordal, F., Fjæraa, A. M., Myhre, G., and Jónasson, K.: Cosmic rays, cloud condensation nuclei and clouds - a reassessment using MODIS data, Atmos. Chem. Phys., 8, 7373-7387, doi:10.5194/acp-8-7373-2008, 2008.

Krivolutsky, A., Kuminov, A., Vyushkova, T., Pereyaslova, N., and Nazarova, M.: Proton activity of the sun during 23rd solar maximum and its response in ozonosphere of the earth, Adv. Space Res., 31, 2151-2156, 2003.

Krivolutsky, A. A., Klyuchnikova, A. V., Zakharov, G. R., Vyushkova, T. Y., and Kuminov, A. A.: Dynamical response of the middle atmosphere to solar proton event of July 2000: Threedimensional model simulations, Adv. Space Res., 37, 16021613, 2006.

Kulmala, M., Riipinen, I., Nieminen, T., Hulkkonen, M., Sogacheva, L., Manninen, H. E., Paasonen, P., Petäjä, T., Dal Maso, M., Aalto, P. P., Viljanen, A., Usoskin, I., Vainio, R., Mirme, S., Mirme, A., Minikin, A., Petzold, A., Hrrak, U., Plaß-Dülmer, C., Birmili, W., and Kerminen, V.-M.: Atmospheric data over a solar cycle: no connection between galactic cosmic rays and new particle formation, Atmos. Chem. Phys., 10, 1885-1898, doi:10.5194/acp-10-1885-2010, 2010.

Laken, B., Wolfendale, A., and Kniveton, D.: Cosmic ray decreases and changes in the liquid water cloud fraction over the oceans, Geophys. Res. Lett., 36, L23803, doi:10.1029/2009GL040961, 2009.

Llewellyn, E., Lloyd, N. D., Degenstein, D. A., Gattinger, R. L., Petelina, S. V., Bourassa, A. E., Wiensz, J. T., Ivanov, E. V., McDade, I. C., Solheim, B. H., McConnell, J. C., Haley, C. S., von Savigny, C., Sioris, C. E., McLinden, C. A., Griffioen, E., Kaminski, J., Evans, W. F. J., Puckrin, E., Strong, K., Wehrle, V., Hum, R. H., Kendall, D. J. W., Matsushita, J., Murtagh, D. P., Brohede, S., Stegman, J., Witt, G., Barnes, G., Payne, W. F., Piche, L., Smith, K., Warshaw, G., Deslauniers, D. L., Marchand, P., Richardson, E. H., King, R. A., Wevers, I., McCreath, W., Kyrola, E., Oikarinen, L., Leppelmeier, G. W., Auvinen, H., Megie, G., Hauchecorne, A., Lefevre, F., de La Noe, J., Ricaud, P., Frisk, U., Sjoberg, F., von Scheele, F., and Nordh, L.: The OSIRIS instrument on the Odin spacecraft, Can. J. Phys., 82, 411-422, doi:10.1139/p04-005, 2004.

Mewaldt, R., Cohen, C., Mason, G., Haggerty, D., and Desai, M.: Long-Term Fluences of Solar Energetic Particles from $\mathrm{H}$ to Fe, Space Sci. Rev., 130, 323-328, 2007.

Mironova, I. A., Desorgher, L., Usoskin, I. G., Flückiger, E. O., and Bütikofer, R.: Variations of aerosol optical properties during the extreme solar event in January 2005, Geophys. Res. Lett., 35, L18610, doi:10.1029/2008GL035120, 2008.

Nieminen, T., Paasonen, P., Manninen, H. E., Sellegri, K., Kerminen, V.-M., and Kulmala, M.: Parameterization of ion-induced nucleation rates based on ambient observations, Atmos. Chem. Phys., 11, 3393-3402, doi:10.5194/acp-11-3393-2011, 2011.

Pallé, E., Butler, C. J., and O'Brien, K.: The possible connection between ionization in the atmosphere by cosmic rays and low level clouds, J. Atmos. Solar-Terr. Phys., 66, 1779-1790, 2004.

Pierce, J. R. and Adams, P. J.: Can cosmic rays affect cloud condensation nuclei by altering new particle formation rates?, Geophys. Res. Lett., 36, L09820, doi:10.1029/2009GL037946, 2009.

Plainaki, C., Belov, A., Eroshenko, E., Mavromichalaki, H., and Yanke, V.: Modeling ground level enhancements: Event of 20 January 2005, J. Geophys. Res., 112, A04102, doi:10.1029/2006JA011926, 2007.

Polyakov, A.V., Timofeev, Yu.M., Virolainen, Ya.A. : Polar stratospheric clouds from satellite observational data, Izvestiya - Atmospheric and Ocean Physics, 44, 448-458, 2008.

Randall, C. E., Harvey, V. L., Singleton, C. S., Bailey, S. M., Bernath, P. F., Codrescu, M., Nakajima, H., and Russell, J. M.: Energetic particle precipitation effects on the Southern Hemisphere stratosphere in 1992-2005, J. Geophys. Res., 112, D08308, doi:10.1029/2006JD007696, 2007.

Semeniuk, K., McConnell, J. C., and Jackman, C. H.: Simulation of the October-November 2003 solar proton events in the CMAM GCM: Comparison with observations, Geophys. Res. Lett., 32, L15S02, doi:10.1029/2005GL022392, 2005.

Seppälä, A., Verronen, P. T., Sofieva, V. F., Tamminen, J., Kyrölä, E., Rodger, C. J., and Clilverd, M. A.: Destruction of the tertiary ozone maximum during a solar proton event, Geophys. Res. Lett., 33, L07804, doi:10.1029/2005GL025571, 2006.

Seppälä, A., Clilverd, M. A., Rodger, C. J., Verronen, P. T., and Turunen, E.: The effects of hard-spectra solar proton events on the middle atmosphere, J. Geophys. Res., 113, A11311, doi:10.1029/2008JA013517, 2008.

Shea, M. A. and Smart, D. F.: A summary of major solar proton events, Solar Phys., 127, 297-320, 1990.

Sonkaew, T., von Savigny, C., Eichmann, K.-U., Weber, M., Rozanov, A., Bovensmann, H., and Burrows, J. P.: Chemical ozone loss in Arctic and Antarctic polar winter/spring season derived from SCIAMACHY limb measurements 20022009, Atmos. Chem. Phys. Discuss., 11, 6555-6599, doi:10.5194/acpd11-6555-2011, 2011.

Svensmark, H., Bondo, T., and Svensmark, J.: Cosmic ray decreases affect atmospheric aerosols and clouds, Geophys. Res. Lett., 36, L15101, doi:10.1029/2009GL038429, 2009.

Tylka, A. and Dietrich, W.: A New and Comprehensive Analysis of Proton Spectra in Ground-Level Enhanced (GLE) Solar Particle Events, in: Proc. 31th Internat. Cosmic Ray Conf., icrc0273, Lodz, Poland, 2009.

Usoskin, I. G. and Kovaltsov, G. A.: Cosmic ray induced ionization in the atmosphere: Full modeling and practical applications, J. Geophys. Res., 111, D21206, doi:10.1029/2006JD007150, 2006.

Usoskin, I. G., Alanko-Huotari, K., Kovaltsov, G. A., and Mursula, K.: Heliospheric modulation of cosmic rays: Monthly reconstruction for 1951-2004, J. Geophys. Res., 110, A12108, doi:10.1029/2005JA011250, 2005.

Usoskin, I. G., Voiculescu, M., Kovaltsov, G. A., and Mursula, K.: Correlation between clouds at different altitudes and solar activity: Fact or Artifact?, J. Atmos. Solar-Terr. Phys., 68, 2164 2172, 2006.

Usoskin, I. G., Kovaltsov, G. A., and Mironova, I. A.: Cosmic ray induced ionization model CRAC:CRII: An extension to the upper atmosphere, J. Geophys. Res., 115, D10302, doi:10.1029/2009JD013142, 2010.

Usoskin, I. G., Kovaltsov, G. A., Mironova, I. A., Tylka, A. J., and Dietrich, W. F.: Ionization effect of solar particle GLE events in low and middle atmosphere, Atmos. Chem. Phys., 11, 19791988, doi:10.5194/acp-11-1979-2011, 2011a.

Usoskin, I. G., Bazilevskaya, G. A., and Kovaltsov, G. A.: Solar modulation parameter for cosmic rays since 1936 reconstructed 
from ground-based neutron monitors and ionization chambers, J. Geophys. Res., 116, A02104, doi:10.1029/2010JA016105, 2011b.

Vainio, R., Desorgher, L., Heynderickx, D., Storini, M., Flückiger, E., Horne, R. B., Kovaltsov, G. A., Kudela, K., Laurenza, M., McKenna-Lawlor, S., Rothkaehl, H., and Usoskin, I. G.: Dynamics of the Earth's Particle Radiation Environment, Space Sci. Rev., 147, 187-231, 2009.

Vitt, F. M. and Jackman, C. H.: A comparison of sources of odd nitrogen production from 1974 through 1993 in the Earth's middle atmosphere as calculated using a two-dimensional model, J. Geophys. Res., 101, 6729-6740, 1996.
Voiculescu, M., Usoskin, I. G., and Mursula, K.: Different response of clouds to solar input, Geophys. Res. Lett., 33, L21802, doi:10.1029/2006GL027820, 2006.

Voiculescu, M., Usoskin, I., and Mursula, K.: Effect of ENSO and volcanic events on the Sun cloud link, Adv. Space Res., 40, 1140-1145, 2007.

Yue, G. K., Lu, C., and Wang, P.: Comparing aerosol extinctions measured by Stratospheric Aerosol and Gas Experiment (SAGE) II and III satellite experiments in 2002 and 2003, J. Geophys. Res., 110, D11202, doi:10.1029/2004JD005421, 2005. 